\title{
Erratum
}

\section{Food sources of nutrients among 13-year-old Portuguese adolescents - Erratum}

\author{
Joana Araujo, Milton Severo, Carla Lopes and Elisabete Ramos
}

First published online 14 July 2011

doi:10.1017/S1368980011001224, Published online by Cambridge University Press 23 June 2011

In the published article the author affiliation ${ }^{1}$ is incorrect.

${ }^{1}$ Department of Clinical Epidemiology, Preventive Medicine and Public Health and Cardiovascular Research \& Development Unity, University of Porto Medical School, Alameda Prof. Hernani Monteiro, 4200-319 Porto, Portugal

It should be as follows:

${ }^{1}$ Department of Clinical Epidemiology, Predictive Medicine and Public Health and Cardiovascular Research \& Development Unity, University of Porto Medical School, Alameda Prof. Hernani Monteiro, 4200-319 Porto, Portugal

The publishers apologise for this error.

\section{Reference}

Araujo J, Severo M, Lopes C and Ramos E. Food sources of nutrients among 13-year-old Portuguese adolescents. Published online by Cambridge University Press 23 June 2011, doi:10.1017/S1368980011001224. 